Article

\title{
Comparison of Aquitaine and Rioja Red Wines: Characterization of Their Phenolic Composition and Evolution from 2000 to 2013
}

\author{
Cindy Quaglieri ${ }^{1,2,+}$, Noelia Prieto-Perea ${ }^{3,+}{ }^{,}$Luis Angel Berrueta ${ }^{3}$, Blanca Gallo ${ }^{3}$, \\ Zurine Rasines-Perea ${ }^{1,2}$, Michael Jourdes ${ }^{1,2}$ and Pierre-Louis Teissedre ${ }^{1,2, *}$ \\ 1 University Bordeaux, ISVV, EA 4577 CEnologie, F-33140 Villenave d'Ornon, France; \\ cindyquaglieri@gmail.com (C.Q.); zuri.rasines@gmail.com (Z.R.-P.); michael.jourdes@u-bordeaux.fr (M.J.) \\ 2 INRA, ISVV, USC 1366 Enologie, F-33140 Villenave d'Ornon, France \\ 3 Departamento de Química Analítica, Facultad de Ciencia y Tecnología, \\ Universidad del País Vasco/Euskal Herriko Unibertsitatea (UPV/EHU), P.O. Box 644, 48080 Bilbao, Spain; \\ noeliap_89@hotmail.com (N.P.-P.); luisangel.berrueta@ehu.eus (L.A.B.); blanca.gallo@ehu.eus (B.G.) \\ * Correspondence: pierre-louis.teissedre@u-bordeaux.fr; Tel.: +33-05-57-57-58-50 \\ + These authors contributed equally to this work.
}

Academic Editor: Marcello Iriti

Received: 3 October 2016; Accepted: 16 January 2017; Published: 24 January 2017

\begin{abstract}
Wine chemical analysis was carried out on 194 commercial blended red wines produced by two major wine-growing areas-the Aquitaine (France) and Rioja (Spain) regions-in order to compare the wines of both regions. Anthocyanins and derived pigments, tannins and derivatives were identified and quantified by HPLC-DAD-ESI-MS/MS (high pressure liquid chromatography coupled to diode array detector and mass spectrometry using the electrospray ionization interface). Mean degree of polymerization (mDP) was determined. The influence of the wine-growing region and the predominance of the properties of some grape varieties used are confirmed by the significant differences observed between both regions. Rioja and Bordeaux "generic" (Bordeaux and Bordeaux-Supérieur appellations) red wines showed the highest anthocyanic content and the highest $\mathrm{mDP}$, as these wines are in a majority made from Merlot (Bordeaux "generic") and Tempranillo (Rioja). On the contrary, Bordeaux "specific" regions (Blayais, Médoc, Graves, and Libournais) showed the red wines with the highest total phenolic content and tannin concentration, as the predominant grape variety used is Cabernet Sauvignon. A principal component analysis (PCA) and a hierarchical ascendant classification (HAC) suggesting patterns between the chemical parameters and the distribution of the red wines in three groups were proposed. The comparison of the two wine-growing areas also reveals some similarities between the various grape varieties used. A general effect of a progressive decrease in anthocyanins, anthocyanin-derived pigment and tannins is observed for older wines.
\end{abstract}

Keywords: wine composition; pigments; tannins; anthocyanins; pyranoanthocyanins; HPLC-DADESI-MS/MS; component levels; Rioja; Aquitaine

\section{Introduction}

Phenolic composition, especially anthocyanin and tannin content, is one of the most important wine attributes. On the one hand, the red wine colour is due to the presence of anthocyanins, directly extracted from grape skins, and anthocyanin-derived pigments, formed during wine-making and ageing. Even though anthocyanins are the principal source of colour for young red wines, they are very reactive at wine $\mathrm{pH}$. A progressive diminution in these monomeric anthocyanins and a simultaneous increase of polymeric pigments as well as color intensity and stability are 
observed. This is the result of interactions among other phenolic compounds, also extracted during the wine-making process [1,2], leading to the stabilization of wine colour. They can react with each other to form anthocyanin oligomers [3,4], or with flavan-3-ol units through a direct condensation or the formation of an ethylidene bridge, leading to the formation of stable red-purple pigments [5]. Anthocyanins also undergo a cycloaddition mechanism to form pyranoanthocyanins, which are distributed in different groups depending on the nature of the structure reacting with the anthocyanin: pyruvic acid (A-type vitisins) [6-8], acetaldehyde (B-type vitisins) [9,10], acetoacetic acid (methylpyrano-anthocyanins) [11,12], vinylphenols (vinylphenol pyranoanthocyanins) or vinylflavanols (flavanol pyranoanthocyanins) [13,14], 4-vinylguaiacol [15], glyoxylic acid [16] or $\alpha$-ketoglutaric acid [9]. Pyranoanthocyanins are more stable than flavan-3-ol/anthocyanin adducts as their additional pyranic ring formed during the cycloaddition step provides more stability towards nucleophilic attack [17].

On the other hand, flavan-3-ols, such as procyanidins (also called condensed tannins), are responsible for wine astringency and bitterness [18,19]. During ageing, tannin polymerization is associated to more softened tannins during wine-tasting [20]. These are also involved in the formation of polymeric anthocyanin/flavan-3-ol or flavan-3-ol/flavan-3-ol adducts, by the way of a direct condensation or indirect condensation through the formation of an ethyl bridge [5].

Previous studies have characterized phenolic contents of one [21-23] or several varietal red wines [24,25], but little is known about the phenolic composition of red wines assembled with two or more grape varieties, from different wine-growing regions compared together in the same study.

This study aims to investigate the phenolic composition of red wines from two major wine-growing areas: Aquitaine in the Southwest of France ( $44^{\circ} 85^{\prime}$ north and $2^{\circ} 44^{\prime}$ west), and Rioja in the North of Spain $\left(42^{\circ} 20^{\prime}\right.$ north and $2^{\circ}$ west). The Aquitaine region has an oceanic climate, whereas the Rioja region has a continental climate. Both are among the most important wine producing regions in the World. Whereas the main red grape varieties used by Rioja wine producers are Tempranillo, Grenache and Graciano, the major red cultivars in Aquitaine are Cabernet Sauvignon, Cabernet Franc and Merlot. The Rioja region is divided in three subregions: Rioja Alta, Rioja Baja and Rioja Alavesa. The Aquitaine region is divided in several subregions, with Médoc, Graves, Blayais and Libournais being some of the most important. Generic Bordeaux denominations (Bordeaux and Bordeaux superior) can be produced in all Aquitaine regions.

Sampling was performed in order to provide a representative overview of the market in each region with a vertical distribution using the red wine samples from 2000 to 2013 vintages (randomly gathered samples). These samples are blended wines, that have been collected and analyzed in a short period of time (February-June 2014), that have been produced using different grape varieties depending on the region and subregion and showing various wine-ageing states and conditions. The investigation of their anthocyanin and flavan-3-ol compositions, anthocyanin-derived pigments contents and mean degree of polymerization aims to highlight a distribution of the samples according to the wine-growing areas, proposing causes such as variety and vintage for any found differences.

\section{Results}

In our study, the phenolic composition of 194 different blended red wines made at different times and distributed between two major wine-growing regions (Aquitaine and Rioja) was analyzed. For the Aquitaine region, wines are divided into six categories, wines come from four subregions: Blayais \& Bourgeais, Médoc, Graves, Libournais on the one hand, which represent "Bordeaux specific" appellations, and Bordeaux and Bordeaux-Supérieur on the other hand, characterizing "Bordeaux generic" appellations. The Rioja region is divided into three subregions: Rioja Alta, Rioja Baja and Rioja Alavesa. The results are presented according to three main contents: anthocyanin and derived-pigment contents, tannin contents and mean degree of polymerization (mDP). 
2.1. Descriptive Analysis of the Phenolic Characterization of Wine Samples: Distribution by Wine-Growing Areas and Vintages

\subsubsection{Anthocyanins and Derived Pigments Contents}

The anthocyanin content distributions for each wine by growing area and by vintage (average values of the data set) are presented in Tables 1 and 2. The distributions of individual anthocyanins, pyranoanthocyanins and polymerized pigments are also evaluated (Table 1A). Total anthocyanin contents are lower in older wines than in the younger wine samples. Separately, the same tendency is observed for Rioja and Aquitaine wines, but with different concentration levels (Figure A1). From 2002 to 2013, Rioja red wines show higher concentrations of total and individual anthocyanins (means of $+109 \%$ and $+93 \%$ towards Aquitaine wines, respectively). "Bordeaux specific" appellations (Blayais, Libournais, Médoc and Graves) show lower concentrations of individual anthocyanins, with totals of $8.10,14.62,18.63$ and $25.61 \mathrm{mg} / \mathrm{L}$, in eq. malvidin-3-O-glucoside (Mv3G), respectively, than "Bordeaux generic" and the Rioja regions (Alta, Alavesa, "Bordeaux generic" and Baja with totals of 31.40, 46.03, 47.19 and $58.92 \mathrm{mg} / \mathrm{L}$ in eq. Mv3G, respectively). Furthermore, Rioja wines show higher concentrations of coumaroylated pigments and lower levels of acetylated ones than Bordeaux wines, as a consequence of differences in the major grape varieties used in each region, as below discussed.

Table 1. Total anthocyanin and tannin contents distributed by wine-growing region (A) and vintage (B).

\begin{tabular}{ccccccc}
\hline \multicolumn{7}{c}{ (A) Distribution by Wine-Growing Region } \\
\hline & \multicolumn{7}{l}{ Total Anthocyanins $(\mathbf{m g} / \mathrm{L})$} & \multicolumn{3}{c}{ Total Tannins (g/L) } \\
\cline { 2 - 7 } & Mean & Std dev & $\boldsymbol{N}$ & Mean & Std dev & $N$ \\
\hline Blayais & 102.43 & \pm 51.09 & 5 & 4.37 & \pm 0.56 & 5 \\
Libournais & 135.71 & \pm 58.50 & 27 & 4.09 & \pm 1.15 & 27 \\
Médoc & 148.21 & \pm 52.93 & 36 & 4.42 & \pm 0.58 & 36 \\
Graves & 180.04 & \pm 51.15 & 13 & 4.05 & \pm 1.16 & 13 \\
Alta & 205.05 & \pm 92.75 & 37 & 4.13 & \pm 0.66 & 37 \\
Bordeaux & 207.31 & \pm 79.68 & 13 & 3.69 & \pm 0.89 & 13 \\
Alavesa & 227.39 & \pm 99.44 & 33 & 4.08 & \pm 0.73 & 33 \\
Baja & 249.86 & \pm 104.21 & 30 & 3.96 & \pm 0.84 & 30 \\
\hline
\end{tabular}

(B) Distribution by vintage

\begin{tabular}{ccccccc}
\hline & \multicolumn{3}{c}{ Total Anthocyanins $(\mathbf{m g} / \mathbf{L})$} & \multicolumn{3}{c}{ Total Tannins $(\mathrm{g} / \mathrm{L})$} \\
\cline { 2 - 7 } & Mean & Std dev & $\boldsymbol{N}$ & Mean & Std dev & $N$ \\
\hline 2000 & 43.32 & \pm 31.65 & 2 & 3.50 & \pm 0.13 & 2 \\
2001 & 254.02 & \pm 246.83 & 2 & 3.45 & \pm 0.23 & 2 \\
2002 & 101.79 & \pm 68.09 & 2 & 3.52 & \pm 0.67 & 2 \\
2003 & 96.90 & \pm 54.70 & 2 & 3.57 & \pm 0.11 & 2 \\
2004 & 116.70 & \pm 69.21 & 8 & 4.61 & \pm 0.87 & 8 \\
2005 & 156.18 & \pm 105.34 & 10 & 4.08 & \pm 0.73 & 10 \\
2006 & 94.26 & \pm 35.41 & 8 & 4.89 & \pm 0.49 & 8 \\
2007 & 156.19 & \pm 31.16 & 14 & 4.13 & \pm 0.40 & 14 \\
2008 & 173.68 & \pm 85.96 & 19 & 4.45 & \pm 0.66 & 19 \\
2009 & 175.19 & \pm 54.52 & 39 & 4.29 & \pm 0.91 & 39 \\
2010 & 202.29 & \pm 55.48 & 49 & 4.10 & \pm 0.94 & 49 \\
2011 & 276.16 & \pm 70.32 & 12 & 4.10 & \pm 0.52 & 12 \\
2012 & 262.35 & \pm 72.31 & 14 & 3.75 & \pm 0.68 & 14 \\
2013 & 332.51 & \pm 85.59 & 12 & 3.18 & \pm 0.41 & 12 \\
\hline
\end{tabular}

Std dev, standard deviation; $N$, number of samples. 
Table 2. Total anthocyanin and tannin contents distributed by subregion and vintages (A) Rioja subregion (B) Bordeaux subregion.

\begin{tabular}{|c|c|c|c|c|c|c|}
\hline \multicolumn{7}{|c|}{ (A) Distribution Vintages and Subregion for Rioja } \\
\hline \multirow{2}{*}{ Subregion } & \multirow{2}{*}{ Vintage } & \multicolumn{2}{|c|}{ Total Anthocyanins (mg/L) } & \multicolumn{2}{|c|}{ Total Tannins (g/L) } & \multirow{2}{*}{$N$} \\
\hline & & Mean & Std dev & Mean & Std dev & \\
\hline \multirow{11}{*}{ Alta } & 2013 & 266.71 & 5.34 & 3.30 & 0.08 & 1 \\
\hline & 2012 & 264.32 & 69.57 & 4.32 & 0.49 & 2 \\
\hline & 2011 & 300.74 & 27.55 & 4.03 & 0.45 & 5 \\
\hline & 2010 & 217.37 & 63.66 & 3.95 & 0.34 & 9 \\
\hline & 2009 & 229.42 & 42.27 & 5.23 & 0.29 & 3 \\
\hline & 2008 & 159.12 & 71.09 & 4.78 & 0.65 & 2 \\
\hline & 2007 & 169.01 & 58.43 & 4.04 & 0.42 & 5 \\
\hline & 2006 & 111.85 & 3.50 & 5.33 & 0.18 & 1 \\
\hline & 2005 & 134.41 & 55.53 & 4.55 & 0.66 & 3 \\
\hline & 2004 & 75.95 & 54.13 & 3.58 & 0.14 & 2 \\
\hline & 2001 & 40.29 & 0.68 & 3.26 & 0.11 & 1 \\
\hline \multirow{11}{*}{ Alavesa } & 2013 & 324.14 & 84.91 & 3.49 & 0.14 & 3 \\
\hline & 2012 & 312.94 & 56.11 & 3.40 & 0.76 & 5 \\
\hline & 2011 & 356.08 & 98.21 & 4.75 & 0.27 & 2 \\
\hline & 2010 & 251.59 & 75.80 & 3.99 & 0.60 & 6 \\
\hline & 2009 & 198.58 & 36.58 & 4.72 & 0.49 & 4 \\
\hline & 2008 & 135.07 & 54.22 & 3.82 & 0.26 & 2 \\
\hline & 2007 & 213.47 & 53.94 & 4.30 & 0.40 & 3 \\
\hline & 2006 & 147.91 & 4.63 & 5.21 & 0.18 & 1 \\
\hline & 2005 & 102.40 & 44.76 & 3.95 & 0.86 & 3 \\
\hline & 2004 & 171.52 & 70.30 & 4.57 & 0.70 & 3 \\
\hline & 2000 & 70.66 & 4.02 & 3.58 & 0.12 & 1 \\
\hline \multirow{11}{*}{ Baja } & 2013 & 361.05 & 82.34 & 3.01 & 0.46 & 7 \\
\hline & 2011 & 219.62 & 40.02 & 3.91 & 0.50 & 5 \\
\hline & 2010 & 176.63 & 41.97 & 4.41 & 0.23 & 3 \\
\hline & 2009 & 207.93 & 64.32 & 4.43 & 0.83 & 4 \\
\hline & 2008 & 299.42 & 65.81 & 5.11 & 0.64 & 4 \\
\hline & 2007 & 114.63 & 62.07 & 3.91 & 0.34 & 4 \\
\hline & 2006 & 143.62 & 4.50 & 4.09 & 0.14 & 1 \\
\hline & 2005 & 294.07 & 143.88 & 3.37 & 0.48 & 2 \\
\hline & 2003 & 144.16 & 4.52 & 3.62 & 0.12 & 1 \\
\hline & 2002 & 160.71 & 5.03 & 2.96 & 0.10 & 1 \\
\hline & 2001 & 67.75 & 7.71 & 3.64 & 0.12 & 1 \\
\hline \multicolumn{7}{|c|}{ (B) Distribution by Vintages and Subregion for Bordeaux } \\
\hline \multirow{2}{*}{ Subregion } & \multirow{2}{*}{ Vintage } & \multicolumn{2}{|c|}{ Total Anthocyanins (mg/L) } & Total & $1 \mathrm{~s}(\mathrm{~g} / \mathrm{L})$ & $N$ \\
\hline & & Mean & Std dev & Mean & Std dev & \\
\hline & 2009 & 160.41 & 10.01 & 4.93 & 0.31 & 2 \\
\hline Blayais & 2008 & 68.17 & 13.51 & 3.81 & 0.16 & 2 \\
\hline & 2005 & 54.12 & 2.42 & 4.39 & 0.15 & 1 \\
\hline & 2010 & 181.81 & 37.56 & 4.27 & 1.19 & 11 \\
\hline & 2009 & 128.54 & 33.34 & 3.84 & 1.26 & 10 \\
\hline & 2008 & 108.71 & 35.36 & 4.23 & 0.48 & 2 \\
\hline Libournais & 2004 & 69.83 & 0.87 & 5.87 & 0.07 & 1 \\
\hline & 2003 & 49.66 & 5.14 & 3.53 & 0.12 & 1 \\
\hline & 2000 & 15.99 & 0.70 & 3.42 & 0.12 & 1 \\
\hline & 2010 & 197.38 & 33.47 & 4.61 & 0.52 & 8 \\
\hline & 2009 & 167.08 & 34.14 & 4.24 & 0.69 & 14 \\
\hline & 2008 & 127.23 & 29.19 & 4.35 & 0.52 & 5 \\
\hline & 2007 & 114.60 & 6.48 & 4.55 & 0.18 & 2 \\
\hline Médoc & 2006 & 68.26 & 14.31 & 4.60 & 0.28 & 3 \\
\hline & 2005 & 107.09 & 4.71 & 4.19 & 0.15 & 1 \\
\hline & 2004 & 98.69 & 49.27 & 5.08 & 0.43 & 2 \\
\hline & 2002 & 42.88 & 0.62 & 4.08 & 0.30 & 1 \\
\hline & 2010 & 199.69 & 29.56 & 3.78 & 1.35 & 8 \\
\hline & 2009 & 240.84 & 9.47 & 4.11 & 0.11 & 1 \\
\hline Graves & 2008 & 156.47 & 29.91 & 4.56 & 0.65 & 2 \\
\hline & 2007 & 128.15 & 5.64 & 3.91 & 0.14 & 1 \\
\hline & 2006 & 61.12 & 5.38 & 5.26 & 0.02 & 1 \\
\hline & 2013 & 223.60 & 9.84 & 3.37 & 0.11 & 1 \\
\hline & 2012 & 224.03 & 69.84 & 3.76 & 0.55 & 6 \\
\hline "Bordeaux generic" & 2010 & 185.01 & 83.56 & 3.29 & 1.15 & 4 \\
\hline & 2009 & 302.39 & 11.89 & 3.50 & 0.08 & 1 \\
\hline & 2006 & 84.83 & 5.51 & 5.39 & 0.11 & 1 \\
\hline
\end{tabular}

Std dev, standard deviation; $N$, number of samples. 
Total and individual anthocyanin contents show a joint evolution with a correlated decrease of each attribute for older wines as compared to younger ones (Figure A1). Separately, the same tendency is observed for Rioja and Aquitaine wines, but with different concentration levels (Table 1A). For Rioja wines, the levels of total and individual anthocyanins are well correlated to the wine "type" and hence to barrel ageing time: Gran Reserva wines show the lowest concentrations (means of $177.64 \mathrm{mg} / \mathrm{L}$ and $13.43 \mathrm{mg} / \mathrm{L}$ for total and individual anthocyanins, respectively), and Joven the highest (means of $299.98 \mathrm{mg} / \mathrm{L}$ and $88.39 \mathrm{mg} / \mathrm{L}$ ). The decreasing concentrations of anthocyanins are due to chemical reactions involving these molecules to form anthocyanin-derived adducts that enhance wine colour and hue.

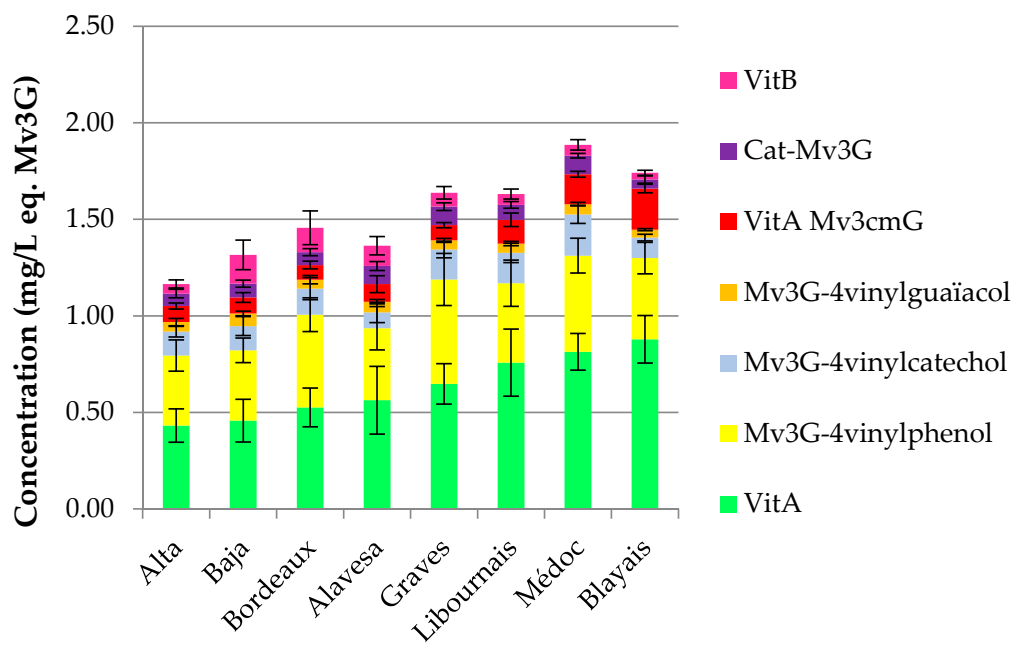

Figure 1. Pyranoanthocyanins and polymerized pigments for each wine-growing region. VitB, vitisin $\mathrm{B}$; Cat-Mv3G, direct catechin-malvidin-3-O-glucoside adduct; VitA Mv3cmG, vitisin A-malvidin-3-Op-coumaroylglucoside; Mv3G-4-vinylguaiacol, pyranomalvidin-3-O-glucoside-4-vinylguaiacol; Mv3G4-vinylcatechol, pyranomalvidin-3-O-glucoside-4-vinylcatechol; Mv3G-4-vinylphenol, pyranomalvidin3-O-glucoside-4-vinylphenol; VitA, vitisin A. Error bars are standard deviation of wine samples within each category.

The distribution of pyranoanthocyanins and polymerized pigments for wines from each area is shown in Figure 1. On the one hand, "Bordeaux specific" wines show a higher content in vitisin A (Mv3G-pyruvic acid) than Rioja and "Bordeaux generic" wines, distributing the wine samples according to their origin and hence varieties, as initially shown for total and individual anthocyanin contents.

Médoc and Blayais wines are richer in vitisin A, catechin-Mv3G and pyranomalvidin-3-Oglucoside-4-vinylphenol derivatives. On the contrary, Rioja and "Bordeaux generic" samples are more concentrated in vitisin B, except for samples from Rioja Alta. Moreover, according to vintage for each wine-growing region, the tendency about the evolution of vitisin A shows a decrease in older wines (Figure 2). 


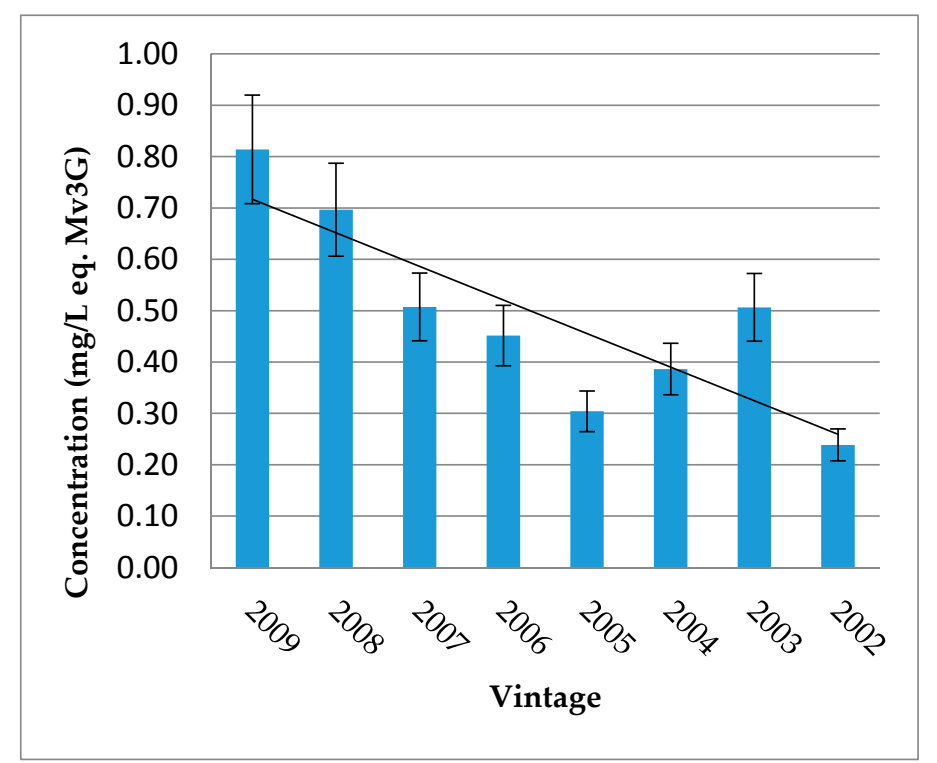

(a)

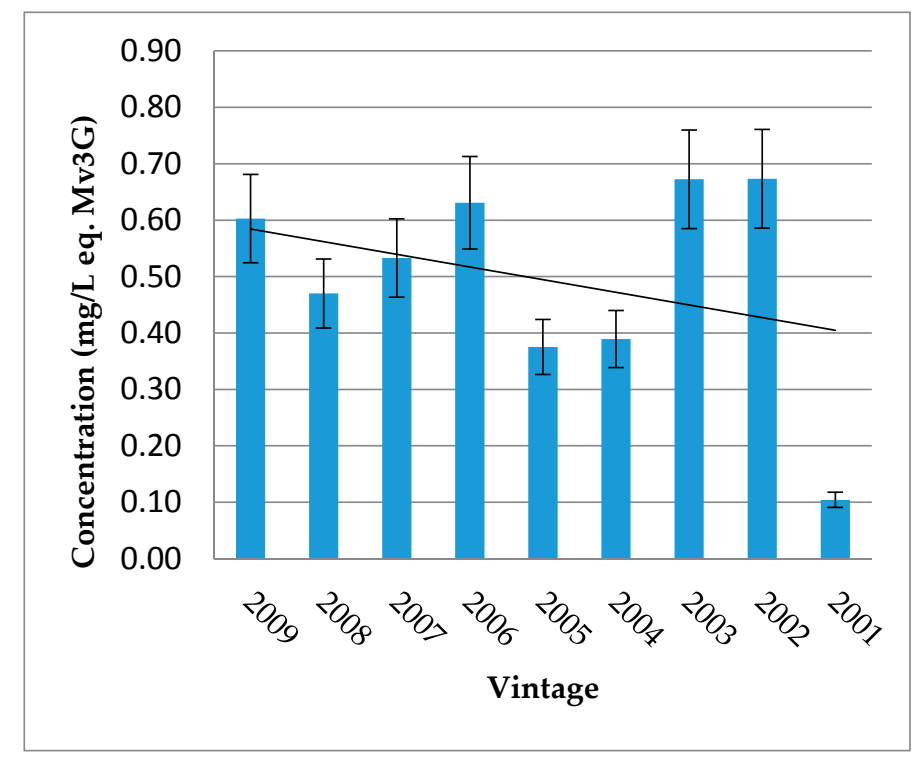

(b)

Figure 2. Distribution of vitisin A by vintage for each wine-growing region: Aquitaine (a) and Rioja (b). Error bars are standard deviation of wine samples within each category.

\subsubsection{Tannin Analyses}

Total tannin content (expressed in $\mathrm{g} / \mathrm{L}$ ) is presented in Tables 1 and 2. Descriptive statistics are also evaluated for low molecular tannins (expressed in $\mathrm{mg} / \mathrm{L} \mathrm{eq.} \mathrm{(+)-catechin)} \mathrm{(Table} \mathrm{A2).}$ $(+)$-Catechin contents are higher than (-)-epicatechin: they are twice higher in "Bordeaux specific" and "Bordeaux generic" samples, three times higher for Rioja Alta and Baja wines, and four times higher for Alavesa ones. Procyanidin dimer B1 is found in higher concentrations than procyanidin dimer B3 for each subregion.

"Bordeaux generic" and "Bordeaux specific" wines are richer in low molecular tannin contents than Rioja wines probably as a consequence of differences in varieties used in each region. The concentration in low molecular tannins $((+)$-catechin, (-)-epicatechin, procyanidin dimers B1 and 
B3, and procyanidin trimer C1) is the highest in Graves samples (average concentration of $194.49 \mathrm{mg} / \mathrm{L}$ eq. (+)-catechin), whereas Alavesa wines show the lowest concentration (103.19 mg/L eq. (+)-catechin), that is twice less than in Graves samples. As regards Bordeaux wines, "Bordeaux generic" samples show the lowest concentrations (153.13 mg/L eq. (+)-catechin).

\subsubsection{Mean Degree of Polymerization}

The mean degree of polymerization is commonly defined as the average number of base tannin units per molecule if the molecules were composed of regularly repeating units, or as the average number of monomeric tannin units per molecule. This value reaches 18 units in a grape seed fraction, and 30 units in grape skin extracts [26,27].

The mDP values for the different wine-growing regions vary from 2.7 to 4.16 (Figure A2). "Bordeaux generic" and "Bordeaux specific" subregions show the lowest mDP with a difference of 1 polymerization unit with Rioja wines (means of mDP 2.9 for all Bordeaux regions, mDP 3.8 for Rioja regions). Considering Rioja wines, $\mathrm{mDP}$ is well correlated with the wine "type" (Figure A3), a difference of 1 polymerization unit is observed between Gran Reserva and Joven wines (mDP 3.18 and 4.14, respectively). This tendency is also noticed from 2000 to 2013, with a decreasing mDP for older wines (Figure A2).

\subsection{Statistical Significance}

The results are confirmed when a principal component analysis over the whole data set was performed. From the nineteen components obtained, the first three with eigenvalues $>1$, were selected, accounting for almost $75 \%$ of the total variance (Figure A4). Figure 3 shows the component weights of 19 original variables, and Figure 4 shows the distribution of the 194 wine samples along the first two principal components (called PC1 and PC2 which explain $66.17 \%$ of the variance).

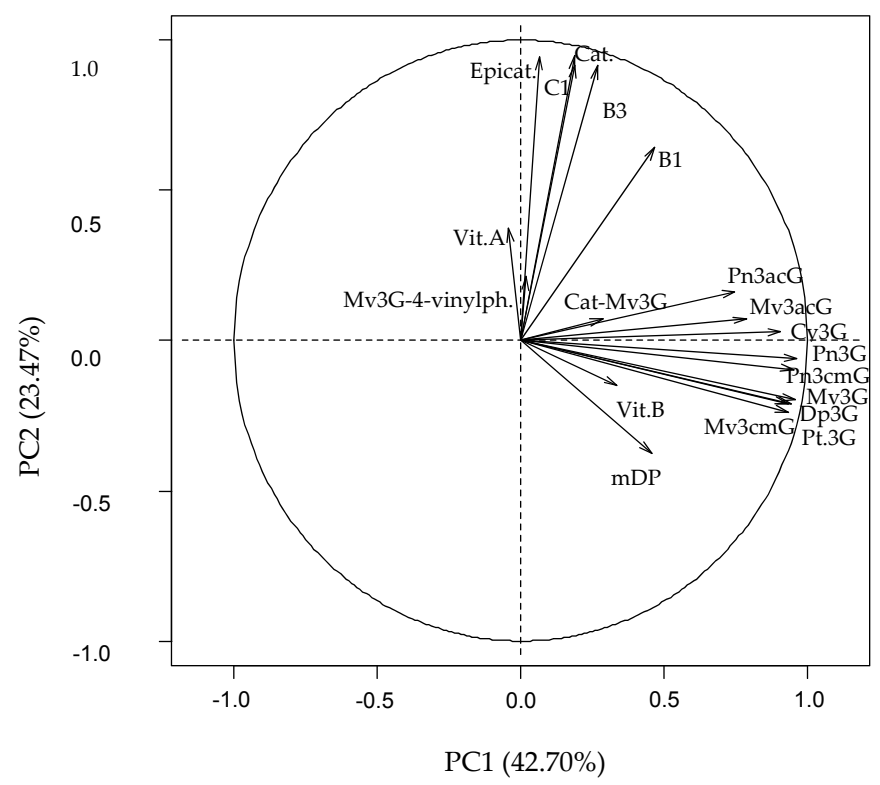

Figure 3. Principal component (PC) analysis. Distribution of samples along PC1 and PC2 and component weights of 19 variables. Mv3G-4-vinylph., pyranomalvidin-3-O-glucoside-4-vinylphenol; Vit.A, Vitisin A; Epicat., Epicatechin; C1, procyanidin trimer C1; Cat., Catechin; B3, procyanidin dimer B3; B1, procyanidin dimer B1; Cat-Mv3G, direct adduct catechin-malvidin-3-O-glucoside; Pn3acG, paeonidin-3-O-acetylglucoside; Mv3acG, malvidin-3-O-acetylglucoside; $\mathrm{Cy3G}$, cyanidin-3O-glucoside; Pn3G, paeonidin-3-O-glucoside; Pn3cmG, paeonidin-3-O-coumaroylglucoside; Mv3G, malvidin-3-O-glucoside; Dp3G, delphinidin-3-O-glucoside; Pt3G, petunidin-3-O-glucoside; Mv3cmG, malvidin-3-O-coumaroylglucoside; Vit.B, vitisin $\mathrm{B}$; $\mathrm{mDP}$, mean degree of polymerization. 


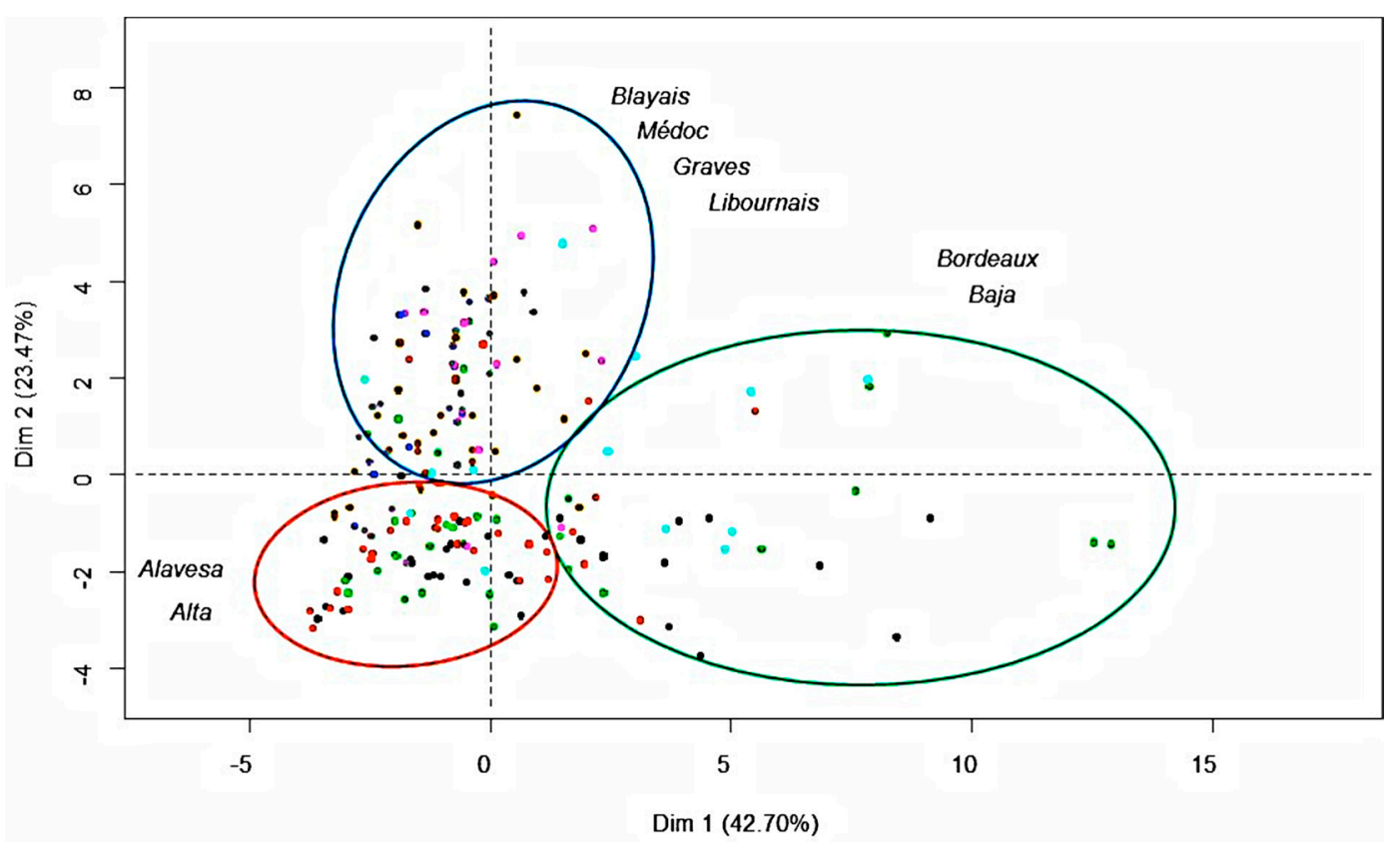

Figure 4. Distribution of the wine samples among PC1 (Dim 1) and PC2 (Dim 2).

\section{Discussion}

\subsection{Anthocyanin and Derived-Pigment Contents}

The analysis of the anthocyanin composition and especially the acylation of anthocyanins can be used to discriminate different grape varieties, such as Tempranillo, Graciano and Cabernet Sauvignon $[28,29]$. Acetylated and $p$-coumaroylated pigments were considered to be important for the characterization of grape varieties $[1,30,31]$. In this study, for the Rioja region, red wines showed higher concentrations of $p$-coumaroyl derivatives but lower acetylated anthocyanin ones than those from "Bordeaux specific" subregions.

Nuñez and co-authors [29] showed significant differences between the anthocyanin distribution and acylation in grape skin extracts from Tempranillo, Graciano and Cabernet Sauvignon. The $p$-coumaroyl derivatives were found in higher quantities in Tempranillo, followed by Graciano and finally Cabernet Sauvignon, whereas acetylated derivatives were more abundant in Cabernet Sauvignon than the two others varieties [29]. Similar results have been also reported by Hebrero et al., who analyzed Tempranillo and compared the results with those obtained from Cabernet Sauvignon previously described by Wulf and Nagel [32,33].

Our results suggest that anthocyanin acylation can be used as a marker to distinguish wine samples in two groups in agreement with the grape variety used, regardless of the region of production. Most of the samples from Rioja, are made from Tempranillo and Graciano richer in $p$-coumaroyl derivatives, whereas Cabernet Sauvignon and Merlot are predominant in Bordeaux red wines, which explains the differences between both groups of wines.

Concerning pyranoanthocyanins and polymerized pigments, "Bordeaux specific" wines show a higher content in vitisin A than Rioja and "Bordeaux generic" wines, distributing the wine samples according to their origin and hence varieties, as initially shown for total and individual anthocyanin contents. The average content for the different vintages of Rioja Alta wines is smaller than that of the wine samples from the other areas (mean of each sample vintage, equal to 2007 which is the oldest mean), suggesting instability of vitisin B and a more stable behaviour of vitisin A, catechin-Mv3G and pyranoanthocyanin-4-vinylphenol adducts during ageing. Then, for Médoc and Graves regions, the proportion of Cabernet Sauvignon and the time of ageing in barrels are also more important than Libournais and Blayais (where Merlot is predominant). The evolution of the concentration in vitisin 
A in these samples show a decreasing trend for older wines, regardless of the wine-growing region (Figure 2). Such a decrease over ageing of vitisin A content was in agreement with the other results found in the literature [34-38]. The authors agreed that maximum of vitisin A content was reached shortly after fermentation, when pyruvic acid is still available, and was followed by a slow decline over ageing [30,31]. Moreover, in Port red wines, where vitisin A was the main pigment found during ageing $[30,36]$, the decrease of this pigment was higher in the wines aged in oak barrels $(15 \%-25 \%)$ than in the bottled samples $(9 \%-18 \%)$. However, it is important to remain critical: for Aquitaine and Rioja wines, there was only one wine for the 2000 vintage. These wines were also not included in the figure since the concentrations in vitisin A were higher than in 2002 (Aquitaine) and 2001 (Rioja). The decreasing tendency found here will need to be confirmed in further studies.

\subsection{Contents of Flavanol Monomer and Procyanidin Dimer and Trimer}

In our wine samples the concentration in (+)-catechin is higher than in (-)-epicatechin, as previously described $[39,40]$. This trend is not typical for one grape variety in particular. Procyanidin dimer B1 is found in higher concentrations than procyanidin dimer B3 for all the wines. Dimer B1 is mainly found in grape skins, and also more extractable during wine-making than dimer B3 mainly located in grape seeds [41-43].

On the one hand, the lowest concentrations in catechin units, procyanidin dimers B1 and B3, and procyanidin trimer $\mathrm{C} 1$ were found in Alavesa wines. After studying the distribution of the grape varieties in Rioja regions, the majority of the red wines produced in Rioja Alavesa is composed of $100 \%$ Tempranillo whereas in the other Rioja regions wines were made with a blend of Tempranillo $(70 \%-80 \%)$ and two other grape varieties: Graciano and Garnacha (10\%-20\% for each one). On the other side, low molecular tannin contents were found in the highest concentrations in Graves wines $((+)$-catechin, (-)-epicatechin, procyanidin dimers B1 and B3, and procyanidin trimer C1). For Graves samples the predominant grape variety used for blend is Cabernet Sauvignon, in which the percentage of low molecular tannins was higher than in Merlot [41,44], which explains here that "Bordeaux generic" samples, that are mainly assembled with Merlot, show the lowest concentrations in low molecular tannins of all the Aquitaine wine-growing subregions.

Like the tendency observed for the anthocyanin analyses, the analysis of tannin composition also divides the samples into two groups: Rioja subregions and "Bordeaux generic" on the one hand and "Bordeaux specific" on the other hand, with a hierarchical richest decreasing approach according to the low molecular tannin contents in the grape varieties used for assembling: Cabernet Sauvignon, Merlot, Graciano and Garnacha, and Tempranillo.

\subsection{Mean Degree of Polymerization}

Using phloroglucinolysis, $\mathrm{mDP}$ values in the range of 1.5-2.5 and 1.3-7.1 have been reported for Bordeaux wines $[45,46]$. In the case of Bordeaux wines, the higher $\mathrm{mDP}$ value is found for Graves (3.36) whose wines are mainly made with Cabernet Sauvignon, which differentiates this region from the others. Previous studies investigated the discrimination of Cabernet Sauvignon from Merlot with the study of proanthocyanidin properties, especially by the way of the calculation of $\mathrm{mDP}$ values [47]. The highest contents in low molecular tannins (catechin units, dimers B1 and B3, and trimer C1), also found in Graves wines, can be correlated to the highest mDP values within "Bordeaux generic" and "specific" wines, explained by the predominance of Cabernet Sauvignon in such wines and the barrel ageing process.

A decrease of mDP values is observed for older wines: Gran Reserva samples show the lowest values, instead of Joven wines (the youngest samples). Chira [48] also reported this tendency with the highlight that $\mathrm{mDP}$ value was correlated to astringency, and that both parameters decreased over ageing, regardless of the grape variety. 
However, the determination of $\mathrm{mDP}$ is based on a reaction in acidic medium, so ethylidene-bridged and oxidized structures may not be measured in this analysis. We presume that linkages from oxidized forms cannot be broken this way, and also that mDP values may differ from those enunciated.

\subsection{Distribution of the Wines Samples by Principal Component Analysis}

After principal component analysis (PCA), red wine samples are distributed in three groups according to two dimensions PC1 and PC2. The first dimension could be called "anthocyanin component", because the variables characterizing the anthocyanin composition are grouped on the positive side of PC1. The variables in component 1 are the sum of the nine major monomers, the catechin-Mv3G adduct, vitisin B and mDP. They present positive weights and are strongly correlated to "Bordeaux generic" and Baja wine regions, most of whose wine samples are distributed in the positive part of this axis. The predominance of Merlot in blended "Bordeaux generic" wines, and the average age of wines from "Bordeaux generic" and Baja samples could explain why both regions are grouped together. Indeed, Merlot grape variety is in a greater proportion in wines than Cabernet Sauvignon and for this reason the samples are correlated to the anthocyanin component. Moreover, the average age of wines from both subregions is higher than for the other regions (2010 for Baja and 2011 for "Bordeaux generic"), and the proportion of monomeric anthocyanins is higher in younger wines.

The separation of the other wine regions is finally achieved with the help of PC2. The second dimension can be called "tannin component", for the variables characterizing the tannin composition are grouped on the positive side of the PC2. The variables with a more important weight in component 2 are the monomers, dimers and trimer of flavan-3-ols. They present positive weights and are strongly correlated to Graves, Médoc, Libournais and Blayais regions, most of whose wine samples are located in the positive part of the axis. For Graves and Médoc, Cabernet Sauvignon is the main grape variety used for blending, which is rich in low molecular flavan-3-ols. The time of ageing in barrels could also support the grouping of these two subregions with Libournais and Blayais. However, information on the ageing conditions is not at our disposal.

Finally, most wine samples of the Rioja Alavesa and Alta regions are distributed on the opposite side, mainly due to their low relative tannin contents. The predominance of Tempranillo in the wines from these subregions also supports such a result. When observing ageing state within each group (from Gran Reserva to young wines in the case of Rioja and from older to more recent vintages for Aquitaine) a tendency to lower anthocyanins and anthocyanin-derivative pigments (lower PC1 values) and tannins (lower PC2 values) contents is clearly noticeable.

\section{Materials and Methods}

\subsection{Reagents and Standards}

Methyl alcohol and acetonitrile (Romil Chemical Ltd., Heidelberg, Germany), trifluoroacetic acid TFA (Merck; Darmstadt, Germany) and acetic acid AcOH (Merck) were HPLC grade. Concentrated aqueous hydrochloric acid $(\mathrm{HCl})$ solution $(32 \%)$ was from Merck. Deionised water was purified on a Milli-Q system (Millipore, Bedford, MA, USA). L(+)-Tartaric acid and ethyl alcohol of analytical grade were provided by Merck. $\mathrm{NaH}_{2} \mathrm{PO}_{4} / \mathrm{Na}_{2} \mathrm{HPO}_{4} 0.1 \mathrm{M}$ solution buffer, which was prepared using monosodium phosphate (Sigma-Aldrich, Steinheim, Germany) and sodium phosphate dibasic (Merck), and sodium hydroxide $\mathrm{NaOH}$ (Panreac, Barcelona, Spain). Solution for phloroglucinolysis was prepared using phloroglucinol and L-ascorbic acid 99\%+reagent (Sigma-Aldrich, St. Louis, MO, USA), hydrochloric acid 37\% and $\mathrm{MeOH}$ with HPLC grade (VWR, Fontenay-sous-Bois, France). Stop solution was prepared using sodium acetate (VWR) and Milli-Q water. Folin-Ciocalteau's phenol reagent, sodium carbonate $99.5 \%+$ granular and gallic acid monohydrate $98 \%+$ were provided by Sigma-Aldrich. Standards of malvidin-3-O-glucoside (Mv-3-glc) and (+)-catechin were supplied by Extrasynthèse (Genay, France). All solvents used were previously filtered through $0.45 \mu \mathrm{m}$ nylon membranes (Lida, Kenosha, WI, USA). 


\subsection{Wine Samples}

A sampling of different red wines made at different times from both Aquitaine and Rioja was performed during January-June 2014 for this study: 94 Aquitaine red wines were from four subregions (wine-growing regions)-Médoc, Graves, Libournais and Blayais \& Bourgeais, called "Bordeaux specific" in this study—and from two generic Bordeaux and Bordeaux-Supérieur appellations, called "Bordeaux generic". 100 Rioja red wines were distributed in the three subregions: Rioja Alta, Rioja Baja and Rioja Alavesa. Rioja wines were divided depending on the time and way of ageing: 26 wines were qualified as young (Joven), 25 as Crianza (at least 12 months aged in oak barrels), 24 as Reserva (36 months of total ageing-barrels and bottles-with at least 12 months aged in oak barrels) and 25 as Gran Reserva (at least 24 months aged in oak barrels followed by 36 months of bottle ageing). The number of wine samples for each vintage and the average age for each subregion are presented in Tables 3 and 4. All the wine samples were collected at the same time and all analyzed during summer 2014.

Table 3. Rioja wines by subregion and style.

\begin{tabular}{|c|c|c|c|c|c|c|c|}
\hline Subregion & Average Age & Range Age & $N$ & Style & Average Age & Range Age & $N$ \\
\hline \multirow{4}{*}{ Alta } & \multirow{4}{*}{2008} & \multirow{4}{*}{ 2001-2013 } & \multirow{4}{*}{34} & Young & 2011 & 2007-2013 & 9 \\
\hline & & & & Crianza & 2010 & 2010-2011 & 9 \\
\hline & & & & Reserva & 2007 & 2004-2009 & 8 \\
\hline & & & & Gran Reserva & 2005 & 2001-2008 & 8 \\
\hline \multirow{4}{*}{ Alavesa } & \multirow{4}{*}{2009} & \multirow{4}{*}{ 2000-2013 } & \multirow{4}{*}{33} & Young & 2012 & 2012-2013 & 8 \\
\hline & & & & Crianza & 2010 & 2009-2011 & 8 \\
\hline & & & & Reserva & 2008 & 2005-2010 & 8 \\
\hline & & & & Gran Reserva & 2005 & 2000-2007 & 9 \\
\hline \multirow{4}{*}{ Baja } & \multirow{4}{*}{2009} & \multirow{4}{*}{$2001-2013$} & \multirow{4}{*}{33} & Young & 2013 & $2011-2013$ & 9 \\
\hline & & & & Crianza & 2010 & 2009-2011 & 8 \\
\hline & & & & Reserva & 2008 & 2007-2009 & 8 \\
\hline & & & & Gran Reserva & 2005 & 2001-2008 & 8 \\
\hline
\end{tabular}

$N$, number of samples.

Table 4. Bordeaux wines by subregion.

\begin{tabular}{cccc}
\hline Subregion & Average Age & Range Age & $N$ \\
\hline Blayais & 2008 & $2005-2009$ & 5 \\
Libournais & 2008 & $2000-2010$ & 26 \\
Médoc & 2008 & $2002-2011$ & 36 \\
Graves & 2009 & $2006-2010$ & 13 \\
"Bordeaux generic" & 2011 & $2006-2013$ & 13 \\
\hline & $N$, number of samples.
\end{tabular}

\subsection{Anthocyanins and Pigment Contents}

\subsubsection{Determination of Total Anthocyanins}

Total anthocyanins are measured using bisulfite bleaching [49]. Two test tubes were filled with $10 \mathrm{~mL}$ of the following mixture: $1 \mathrm{~mL}$ of wine sample, $1 \mathrm{~mL}$ of $\mathrm{EtOH}$ acidified with $0.1 \% \mathrm{HCl}$ and $20 \mathrm{~mL}$ of $\mathrm{HCl}$ concentrated at $2 \%$. In the first tube $4 \mathrm{~mL}$ of $\mathrm{H}_{2} \mathrm{O}$ was added (DOref, optical density), and in the second $4 \mathrm{~mL}$ of sodium bisulfite at 15\% (DOt). After $20 \mathrm{~min}$ of reaction, the optical density was measured at $520 \mathrm{~nm}$ for each tube, and the result was given following this relation: $[\mathrm{C}](\mathrm{mg} / \mathrm{L})=875 \times\left(\mathrm{DO}_{\mathrm{t}}-\mathrm{DO}_{\mathrm{ref}}\right)$.

\subsubsection{Analysis of Individual Anthocyanins}

Individual anthocyanins were evaluated using the official method adopted by OIV (Vines and Wines International Organization) [50]. Determination of relative composition for the nine main 
individual anthocyanins in red wines was evaluated. Samples were directly filtered on a $0.45 \mu \mathrm{m}$ membrane and analyzed using HPLC. The system used was an Accela series (Thermo-Scientific, Illkirch-Graffenstaden, France). The analysis was carried out on a $4 \times 250 \mathrm{~mm}$ internal diameter (i.d.), $5 \mu \mathrm{m}$ Nucleosil C18 column (Agilent, Les Ulis, France). The solvents used were A: $\mathrm{H}_{2} \mathrm{O} / \mathrm{HCOOH}(95: 5)$ and B: acetonitrile/ $\mathrm{HCOOH}(95: 5)$. The gradient consisted of: $10 \%-35 \% \mathrm{~B}$ in $25 \mathrm{~min}$, and $35 \%-100 \% \mathrm{~B}$ in $1 \mathrm{~min}$ at a flow rate of $1 \mathrm{~mL} / \mathrm{min}$. The column was washed with $100 \% \mathrm{~B}$ for $5 \mathrm{~min}$ and re-equilibrated with the initial conditions for $5 \mathrm{~min}$. Quantification was performed using an external standard of malvidin-3-O-glucoside (Mv3G).

\subsubsection{Analysis of Anthocyanin-Derived Pigments}

Wine samples were first clean up on Strata $X$ cartridges (reversed-phase commercial Solid Phase Extraction (SPE) cartridges, Phenomenex, Torrance, CA, USA) previously conditioned with $\mathrm{MeOH}$ and synthetic wine, washed with $0.1 \mathrm{~mol} / \mathrm{L}$ of phosphate buffer $(\mathrm{pH}=6.5)$, which eluted phenolic acids, in order to reduce the effect of ionic saturation during HPLC-ESI-MS/MS analysis. The fraction of interest, eluted with acidic methanol $(\mathrm{MeOH} / \mathrm{HCl}, 999: 1)$, evaporated to dryness and solubilized in Milli-Q water acidified with TFA (995:5), was analysed with an Alliance 2695 HPLC instrument (Waters, Saint Quentin Yvelines, France) equipped with a $100 \times 3.0 \mathrm{~mm}$ i.d., Onyx Monolithic C18 column (Phenomenex) thermostated at $30{ }^{\circ} \mathrm{C}$. Detection was carried out at $530 \mathrm{~nm}$, and complete spectral data were accumulated in the range 250-600 nm each second, using a Waters Alliance 2996 diode-array detector (DAD). Mass detection was carried out using a Quattro triple quadrupole mass spectrometer (Micromass, Guyancourt, France) equipped with a Z-spray electrospray ionization (ESI) source, performed in positive mode and without flow split, with the following parameters: capillary voltage $3.2 \mathrm{kV}$, extraction cone voltage $3 \mathrm{~V}$, hexapole lenses voltage $0 \mathrm{~V}$, source temperature $120^{\circ} \mathrm{C}$, desolvation temperature $300^{\circ} \mathrm{C}$ and desolvation gas flow $450 \mathrm{~L} / \mathrm{h}$. The solvents used were solvent A: $\mathrm{H}_{2} \mathrm{O} / \mathrm{TFA}(995: 5 \mathrm{v} / \mathrm{v})$ and $\mathrm{B}: \mathrm{CH}_{3} \mathrm{CN}$.The gradient consisted of $12 \% \mathrm{~B}$ isocratic during $0.29 \mathrm{~min}$, linear gradient $12 \%-15 \%$ B in $4 \mathrm{~min}$, then $15 \%-25 \%$ B from 4.29 to $9.17 \mathrm{~min}, 25 \%-40 \%$ B from 9.17 to $12.72 \mathrm{~min}$, then isocratic $40 \%$ B from 12.72 to $13.17 \mathrm{~min}$, finally $40 \%-100 \%$ B in $0.5 \mathrm{~min}$. The column was washed with $100 \%$ B for 8 min and then reconditioned with initial conditions. The injection volume was $50 \mu \mathrm{L}$. The flow rate was $0.3 \mathrm{~mL} / \mathrm{min}$. Quantitation was performed using Multiple Reaction Monitoring (MRM) mode (Table 5). An external standard of Mv3G was used. [51].

Table 5. Analysis of anthocyanin-derived pigments: parameters for multiple reaction monitoring (MRM).

\begin{tabular}{cccc}
\hline Analyte & Mass Transition & Cone Voltage (V) & Collision Energy (eV) \\
\hline Mv3G-acetaldehyde & $517 \rightarrow 355$ & 25 & 25 \\
Mv3 $p$-coumG-acetaldehyde & $663 \rightarrow 355$ & 35 & 25 \\
Mv3G-pyruvic acid & $561 \rightarrow 399$ & 25 & 25 \\
Mv3p-coumG-pyruvic acid & $707 \rightarrow 399$ & 35 & 25 \\
Mv3G-vinylmethyl & $531 \rightarrow 369$ & 25 & 25 \\
Mv3G-vinylphenol & $609 \rightarrow 447$ & 25 & 25 \\
Mv3p-coumG-vinylphenol & $755 \rightarrow 447$ & 35 & 25 \\
Mv3G-vinylcatechol & $625 \rightarrow 463$ & 35 & 25 \\
Mv3G-vinylguaiacol & $639 \rightarrow 447$ & 35 & 25 \\
Mv3p-coumG-vinylguaiacol & $785 \rightarrow 447$ & 35 & 35 \\
Cat-Mv3G & $781 \rightarrow 619$ & 35 & 25 \\
Cat-Mv3 $p$-coumG & $927 \rightarrow 619$ & 35 & 25 \\
Epicat-Mv3G & $781 \rightarrow 619$ & 35 & 25 \\
(Epi)Gallocat-Mv3G & $797 \rightarrow 635$ & 35 & 25 \\
Mv3 $p$-coumG-8-ethyl-(epi)cat & $955 \rightarrow 665$ & 35 & 25 \\
\hline
\end{tabular}




\subsection{Flavan-3-ol Contents}

\subsubsection{Determination of Total Tannins}

Total tannins were measured using the Bate-Smith reaction [52]. Two test tubes were filled with $2 \mathrm{~mL}$ of wine sample (dilution 1/50), $1 \mathrm{~mL}$ of distilled water and $3 \mathrm{~mL}$ of $\mathrm{HCl} 37 \%$. One of the tubes was tightly capped and hydrolyzed at $100{ }^{\circ} \mathrm{C}$ during $30 \mathrm{~min}$. After the hydrolysis, $500 \mu \mathrm{L} \mathrm{of} \mathrm{EtOH}$ were added in each tube. The optical density (DO) was measured at $550 \mathrm{~nm}$ with an optical path length of $1 \mathrm{~cm}$. Tannin concentration was given following this relation: $[\mathrm{C}](\mathrm{g} / \mathrm{L})=19.33 \times \Delta \mathrm{DO}$.

\subsubsection{Determination of Individual Tannins}

Tannins were analysed and measured with HPLC-ESI-MS(-)-CID-MS/MS (high-performance liquid chromatography-electrospray ionization collision-induced dissociation tandem mass spectrometry) analysis. Wine samples were previously fractionated on SPE system, which was a hydrophilic polymeric sorbent Oasis HLB (Waters Corporation). The obtained fractions of wine were solubilized in $1 \mathrm{~mL}$ of $\mathrm{H}_{2} \mathrm{O} / \mathrm{AcOH}$ (99:1). HPLC material was described above (see Section 4.3.3). The mass parameters were: capillary voltage $2.6 \mathrm{kV}$ in negative mode, source temperature $120^{\circ} \mathrm{C}$, extraction cone voltage $3 \mathrm{~V}$, hexapole lenses voltage $0 \mathrm{~V}$, source temperature $120^{\circ} \mathrm{C}$, desolvation temperature $300{ }^{\circ} \mathrm{C}$ and desolvation gas flow $450 \mathrm{~L} / \mathrm{h}$. The solvents used were solvent $\mathrm{A}: \mathrm{H}_{2} \mathrm{O} / \mathrm{AcOH}$ $(99: 1 \mathrm{v} / \mathrm{v})$ and B: methyl alcohol/AcOH (99:1 v/v). The gradient consisted of 0\% B during $1.03 \mathrm{~min}$, from 0 to $20 \%$ B from 1.03 to $7.47 \mathrm{~min}$, from $20 \%$ to $25 \%$ B from 7.47 to $11.25 \mathrm{~min}$, from $25 \%$ to $45 \%$ B from 11.25 to $16.03 \mathrm{~min}$, then from $45 \%$ to $75 \%$ B from 16.03 to $19.92 \mathrm{~min}$, finally from $75 \%$ to $100 \% \mathrm{~B}$ from 19.92 to $24.70 \mathrm{~min}$. The column was washed with 100\% B during $3 \mathrm{~min}$, then reconditioned with the initial conditions. The injection volume was $50 \mu \mathrm{L}$. The flow rate was $0.3 \mathrm{~mL} / \mathrm{min}$. [53]. Tannin quantification was performed using an external standard of $(+)$-catechin between the ranges of 0.005 and $150 \mathrm{mg} / \mathrm{L}$, and MRM mode (Table 6).

Table 6. Determination of individual tannins: parameters of multiple reaction monitoring.

\begin{tabular}{cccc}
\hline Molecule & Mass Transition & Cone Voltage (V) & Collision Energy (eV) \\
\hline (+)-catechin & $289 \rightarrow 137$ & 25 & 25 \\
(-)-epicatechin & $289 \rightarrow 137$ & 25 & 25 \\
(+)-gallocatechin & $305 \rightarrow 137$ & 25 & 25 \\
$(-)$-epigallocatechin & $305 \rightarrow 137$ & 25 & 25 \\
Procyanidin B dimers & $577 \rightarrow 289$ & 25 & 25 \\
Prodelphinidin B dimers & $609 \rightarrow 305$ & 25 & 25 \\
Mixed B dimers & $593 \rightarrow 305$ & 35 & 25 \\
Procyanidins B trimers & $865 \rightarrow 577$ & 25 & 25 \\
Procyanidin A dimers & $575 \rightarrow 285$ & 15 & 25 \\
Mixed A dimers & $591 \rightarrow 303$ & 55 & 25 \\
Vinyl-flavan-3-ols & $879 \rightarrow 591$ & 35 & 25 \\
Procyanidin dimers with furfuryl bridge & $315 \rightarrow 163$ & 55 & 25 \\
Glycosylated flavan-3-ols & $451 \rightarrow 289$ & 55 & 25 \\
\end{tabular}

\subsection{Determination of Mean Degree of Polymerization}

The proanthocyanidin mDP concentrations were quantified by phloroglucinolysis [45]. The oligomeric and polymeric proanthocyanidins were depolymerised in the presence of a nucleophilic agent phloroglucinol in an acidic medium. Reversed-phase HPLC analysis of the products formed allows determination of the structural composition of proanthocyanidins, which are characterised by the nature of their constitutive extension units (released as flavan-3-ols phloroglucinol adducts) and terminal units (released as flavan-3-ols). To calculate the apparent mDP, the sum of all subunits (flavan-3-ol monomer and phloroglucinol adducts, in mols) was divided by the sum of all flavan-3-ol monomers (in mols). Wine samples were analysed with a Surveyor series instrument (Thermo-Finnigan, Les Ullis, France) equipped with a $100 \times 4.6 \mathrm{~mm}$ i.d., $3.5 \mu \mathrm{m}$ X-Terra reversed-phase 
$\mathrm{C} 18$ column (Waters) thermostated at $25^{\circ} \mathrm{C}$. Detection was carried out at $280 \mathrm{~nm}$ using a Finnigan Surveyor PDA Plus detector. The mass detection was carried out using a Finnigan LCQ DECA XP MAX mass spectrometer with an ESI interface, performed in positive mode with the following parameters: capillary temperature $325^{\circ} \mathrm{C}$, capillary voltage $4 \mathrm{~V}$, nebulizer gas flow $1.75 \mathrm{~L} / \mathrm{min}$, desolvation gas flow $1 \mathrm{~L} / \mathrm{min}$, and spray voltage $5 \mathrm{kV}$. The solvents used were solvent $\mathrm{A}: \mathrm{H}_{2} \mathrm{O} / \mathrm{AcOH}(99: 1 \mathrm{v} / \mathrm{v})$, and $\mathrm{B}: \mathrm{MeOH}$. The gradient consisted of $5 \% \mathrm{~B}$ during $25 \mathrm{~min}$, linear gradient $5 \%-20 \% \mathrm{~B}$ in $20 \mathrm{~min}$, then $20 \%-32 \%$ B in $15 \mathrm{~min}$, finally $32 \%-100 \%$ B in $2 \mathrm{~min}$. The column was washed with $100 \%$ B for $5 \mathrm{~min}$ and then stabilized with the initial conditions for $10 \mathrm{~min}$. The injection volume was $20 \mu \mathrm{L}$. The flow rate was $1 \mathrm{~mL} / \mathrm{min}$.

\subsection{Data Analysis}

Statistical data analysis was performed using Statistica v.10 (Statsoft Inc., Tulsa, OK, USA). Descriptive statistics were realized for each chemical variable. Then a principal component analysis was performed using $R$ to examine any possible grouping of samples according to wine-growing regions and vintages. PCA was performed on the correlation matrix using a few attributes that well characterize the phenolic composition of the wine samples.

\section{Conclusions}

This study shows significant differences between red wines from Rioja and those from Aquitaine. Although the samples are blended wines, there is a strong discrimination between the grape varieties, as previously described. $p$-coumaroylated pigments were found in higher concentrations in red wines from the Rioja area, for they are made from Tempranillo and Graciano varieties; whereas the proportion of acylated ones was higher in red wines from the Aquitaine area, in agreement with previous studies on the grape skin composition of Cabernet Sauvignon. Vitisin A content shows a decreasing trend when wines are older. The concentration of individual tannins is higher in "Bordeaux specific" red wines, especially for the samples where Cabernet Sauvignon is predominant.

According to the hierarchical ascendant classification, wine samples are scattered in three classes of wine regions and this result confirms the discrimination of wine regions according to PC1 and PC2. The first class effectively groups "Bordeaux generic" and Rioja Baja wines, which attributes were individual anthocyanins, mDP, polymerized pigments (catechin-Mv3G adduct) and vitisin B; the second class groups Blayais, Médoc, Graves and Libournais wines, characterized by monomers and dimers of flavan-3-ols, vinylphenol pyranoanthocyanins, and vitisin A; and finally, the last class is represented by Rioja Alavesa and Alta wines, contrary to the second class, since most of wine samples from these areas are mainly blended with Tempranillo. This separation by regions is mainly a consequence of the different varieties used by wine producers in each region. Ageing has a general effect of progressively decreasing anthocyanins, anthocyanin-derived pigment and tannins.

Acknowledgments: This work was funded by financial support of the EUROREGION Aquitaine-Euskadi: Project No. 2014-0114, Contenido en taninos y antocianos de los vinos tintos: Comparación entre los vinos de Burdeos y de Rioja. Authors also thank to the wineries Faustino, Cvne, Unión de Cosecheros de Labastida S Coop., La Rioja Alta, Bodegas Luis Cañas, El Coto de Rioja, Granja Nuestra Señora de Remelluri, Bodegas Riojanas, Viñedos Real Rubio, Viñedos de Aldeanueva S. Coop., Bodegas Domeco de Jarauta, Marqués de Reinosa S. Coop., Eguren Ugarte, Bodegas Valdemar, Bodegas Bilbaínas, Bodegas Roda, Bodegas Franco-Españolas, Bodegas LAN, Bodegas Campo Viejo, Unión Viti-Vinícola, Bodegas Bagordi, Bodegas del Medievo, Vinícola Riojana de Alcanadre, Bodegas y Viñedos Quinta Avenida, Bodegas Criadores de Rioja and Bodegas de los Herederos de Marqués de Riscal for their collaboration as well as Bordeaux wineries involved in the project.

Author Contributions: L.A.B., B.G., M.J. and P.L.T. conceived and designed the experiments and analyzed the results; C.Q., N.P.-P., Z.R.-P. performed the experiments, analyzed results and wrote the paper.

Conflicts of Interest: The authors declare no conflict of interest. 


\section{Appendix A}

Table A1. Descriptive statistics of the anthocyanin and derived pigment contents for each wine region, expressed in mg/L in equivalent malvidin-3-O-glucoside.

\begin{tabular}{ccccccccccccccccccc}
\hline $\boldsymbol{N}$ & \multicolumn{2}{c}{ Alavesa 33 } & \multicolumn{2}{c}{ Alta 34 } & \multicolumn{2}{c}{ Baja 33 } & \multicolumn{2}{c}{ Blayais 5 } & \multicolumn{2}{c}{ Bordeaux 13 } & \multicolumn{2}{c}{ Graves 13 } & Libournais 27 & Médoc 36 \\
\hline Dp3G & 6.53 & \pm 5.70 & 4.43 & \pm 3.55 & 7.58 & \pm 7.10 & 0.95 & \pm 0.34 & 5.59 & \pm 3.99 & 3.15 & \pm 1.77 & 1.94 & \pm 1.32 & 2.21 & \pm 1.41 \\
Cy3G & 0.83 & \pm 0.59 & 0.67 & \pm 0.28 & 1.53 & \pm 3.25 & 0.47 & \pm 0.09 & 1.00 & \pm 0.52 & 0.71 & \pm 0.18 & 0.63 & \pm 0.23 & 0.67 & \pm 0.25 \\
Pt3G & 6.20 & \pm 5.28 & 4.21 & \pm 3.63 & 7.41 & \pm 7.27 & 0.75 & \pm 0.24 & 4.56 & \pm 2.98 & 2.64 & \pm 1.77 & 1.70 & \pm 1.58 & 1.80 & \pm 1.11 \\
Pn3G & 2.75 & \pm 2.34 & 2.00 & \pm 1.42 & 4.51 & \pm 4.65 & 0.96 & \pm 0.18 & 3.63 & \pm 2.32 & 1.82 & \pm 0.84 & 1.26 & \pm 0.66 & 1.44 & \pm 0.93 \\
Mv3G & 23.42 & \pm 20.7 & 15.27 & \pm 14.43 & 28.44 & \pm 26.93 & 2.32 & \pm 1.11 & 21.34 & \pm 13.57 & 11.94 & \pm 8.88 & 5.48 & \pm 3.69 & 8.00 & \pm 4.88 \\
Pn3acG & 0.55 & \pm 0.23 & 0.47 & \pm 0.17 & 1.21 & \pm 3.25 & 0.41 & \pm 0.05 & 1.32 & \pm 0.69 & 0.68 & \pm 0.23 & 0.52 & \pm 0.19 & 0.57 & \pm 0.18 \\
Mv3acG & 2.43 & \pm 1.85 & 1.81 & \pm 1.41 & 3.13 & \pm 3.40 & 1.04 & \pm 0.34 & 6.58 & \pm 4.08 & 2.56 & \pm 1.47 & 1.61 & \pm 1.01 & 2.22 & \pm 1.39 \\
Pn3cmG & 0.69 & \pm 0.28 & 0.58 & \pm 0.22 & 1.42 & \pm 3.23 & 0.45 & \pm 0.08 & 0.89 & \pm 0.34 & 0.60 & \pm 0.10 & 0.49 & \pm 0.10 & 0.51 & \pm 0.11 \\
Mv3cmG & 2.68 & \pm 1.82 & 1.99 & \pm 1.67 & 3.76 & \pm 3.69 & 0.75 & \pm 0.25 & 2.54 & \pm 1.40 & 1.51 & \pm 1.00 & 0.99 & \pm 0.42 & 1.21 & \pm 0.59 \\
Vit. A & 0.56 & \pm 0.17 & 0.43 & \pm 0.22 & 0.46 & \pm 0.20 & 0.88 & \pm 0.25 & 0.53 & \pm 0.19 & 0.65 & \pm 0.21 & 0.76 & \pm 0.35 & 0.81 & \pm 0.35 \\
Vit. B & 0.10 & \pm 0.09 & 0.05 & \pm 0.04 & 0.15 & \pm 0.15 & 0.04 & \pm 0.02 & 0.13 & \pm 0.17 & 0.07 & \pm 0.06 & 0.06 & \pm 0.05 & 0.06 & \pm 0.05 \\
Mv3G-4-vinylph. & 0.43 & \pm 0.05 & 0.41 & \pm 0.04 & 0.43 & \pm 0.05 & 0.46 & \pm 0.04 & 0.52 & \pm 0.05 & 0.59 & \pm 0.07 & 0.46 & \pm 0.07 & 0.55 & \pm 0.06
\end{tabular}

N, Number of samples; Dp3G, delphinidin-3-O-glucoside; Cy3G, cyanidin-3-O-glucoside; Pt3G, petunidin-3-O-glucoside; Pn3G, paeonidin-3-O-glucoside; Mv3G, malvidin-3-O-glucoside; Pn3acG, paeonidin-3-O-acetylglucoside; Mv3acG, malvidin-3-O-acetylglucoside; Pn3cmG, paeonidin-3-O-coumaroylglucoside; Mv3cmG, malvidin-3-O-coumaroylglucoside; Vit.A, vitisin A; Vit.B, vitisin B; Mv3G-4-vinylph, pyranomalvidin-3-O-glucoside-4-vinylphenol.

Table A2. Descriptive statistics of the tannin content for each wine region, expressed in $\mathrm{mg} / \mathrm{L}$ in equivalent $(+)$-catechin.

\begin{tabular}{ccccccccccccccccc}
\hline $\boldsymbol{N}$ & \multicolumn{1}{c}{ Alavesa 33 } & \multicolumn{2}{c}{ Alta 34 } & \multicolumn{2}{c}{ Baja 33 } & \multicolumn{3}{c}{ Blayais 5 } & \multicolumn{3}{c}{ Bordeaux 13 } & \multicolumn{2}{c}{ Graves 13 } & Libournais 27 & Médoc 36 \\
\hline Cat-Mv3G & 0.09 & \pm 0.04 & 0.06 & \pm 0.04 & 0.07 & \pm 0.04 & 0.05 & \pm 0.03 & 0.07 & \pm 0.02 & 0.10 & \pm 0.04 & 0.08 & \pm 0.03 & 0.10 & \pm 0.04 \\
(+)-cat. & 42.97 & \pm 9.47 & 49.48 & \pm 16.86 & 54.75 & \pm 18.39 & 75.32 & \pm 21.76 & 64.93 & \pm 18.91 & 77.37 & \pm 17.57 & 69.92 & \pm 15.67 & 66.29 & \pm 13.90 \\
(-)-epicat. & 9.78 & \pm 4.94 & 14.82 & \pm 11.80 & 19.48 & \pm 10.74 & 31.67 & \pm 15.74 & 29.70 & \pm 17.01 & 38.25 & \pm 14.54 & 32.95 & \pm 10.58 & 30.63 & \pm 12.55 \\
B1 & 30.65 & \pm 9.12 & 30.24 & \pm 12.02 & 29.05 & \pm 11.88 & 30.36 & \pm 8.79 & 30.68 & \pm 9.18 & 40.77 & \pm 9.80 & 33.15 & \pm 10.99 & 31.04 & \pm 10.89 \\
B3 & 10.37 & \pm 3.77 & 12.17 & \pm 6.69 & 14.01 & \pm 7.19 & 15.17 & \pm 7.47 & 17.85 & \pm 9.14 & 25.63 & \pm 10.71 & 21.08 & \pm 8.30 & 19.17 & \pm 9.26 \\
C1 & 5.17 & \pm 0.90 & 5.59 & \pm 1.60 & 6.08 & \pm 1.90 & 7.01 & \pm 1.54 & 6.96 & \pm 1.82 & 9.01 & \pm 2.22 & 7.83 & \pm 1.84 & 7.39 & \pm 1.88 \\
mDP & 4.16 & \pm 1.15 & 3.62 & \pm 0.82 & 3.50 & \pm 0.61 & 2.76 & \pm 0.22 & 2.94 & \pm 0.68 & 3.36 & \pm 0.40 & 2.70 & \pm 0.64 & 2.90 & \pm 0.49 \\
\hline
\end{tabular}

$\mathrm{N}$, Number of samples; Cat-Mv3G, catechin-malvidin-3-O-glucoside; (+)-cat., (+)-catechin; (-)-epicat., (-)-epicatechin; B1, procyanidin dimer B1; B3, procyanidin dimer B3; C1, procyanidin trimer $\mathrm{C} 1$; $\mathrm{mDP}$, mean degree of polymerisation. 


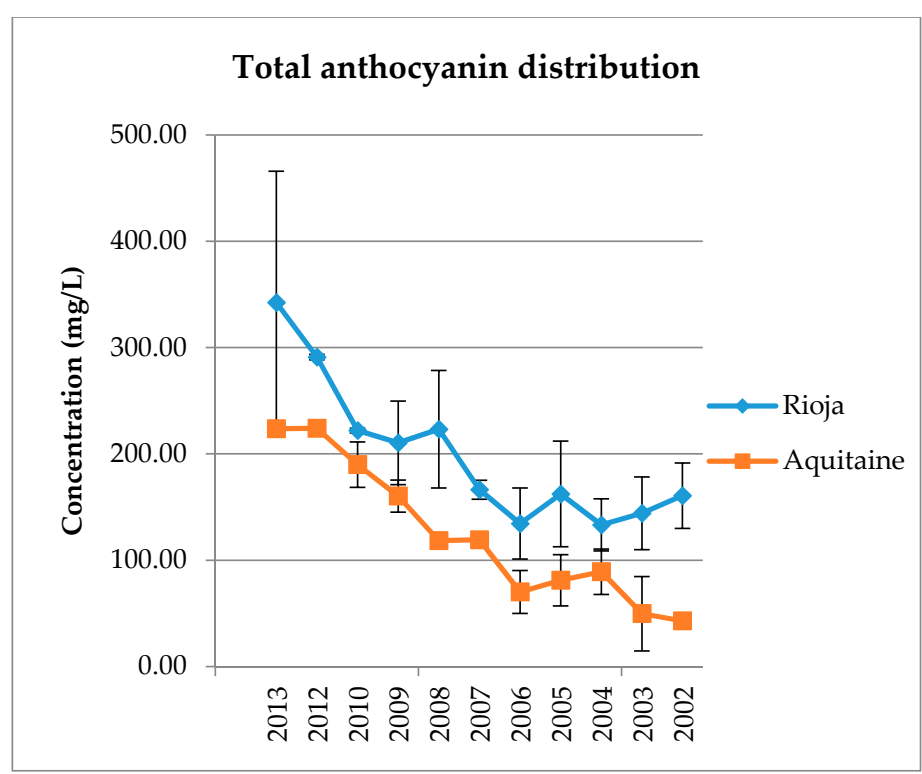

(a)

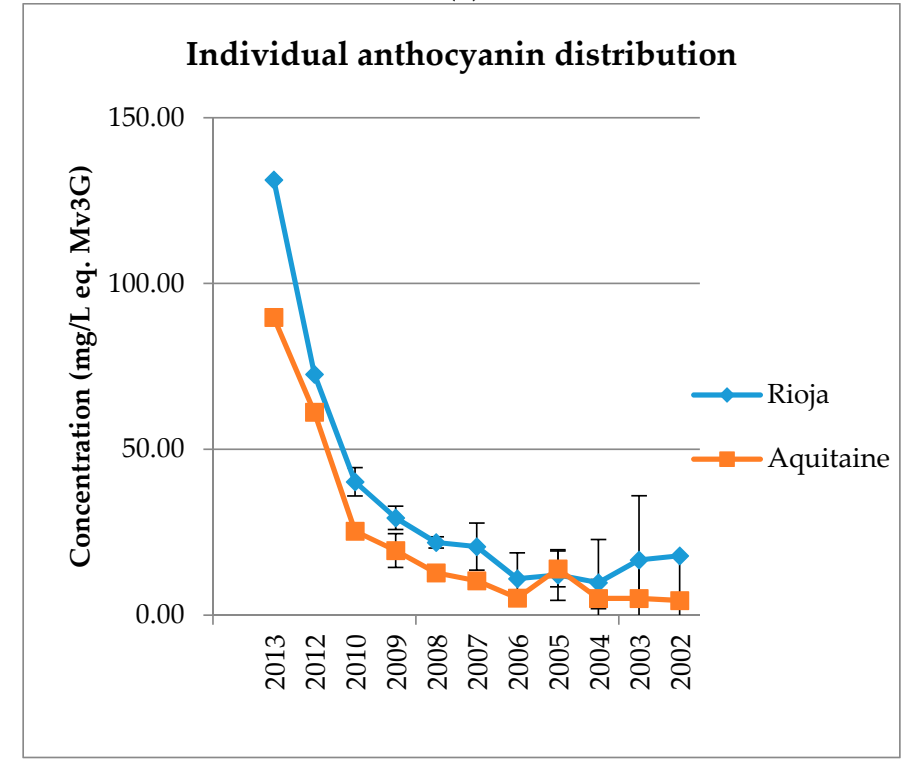

(b)

Figure A1. Total (a) and individual (b) anthocyanin distribution for Rioja and Aquitaine wines. Error bars are standard deviation of wine samples within each category. 


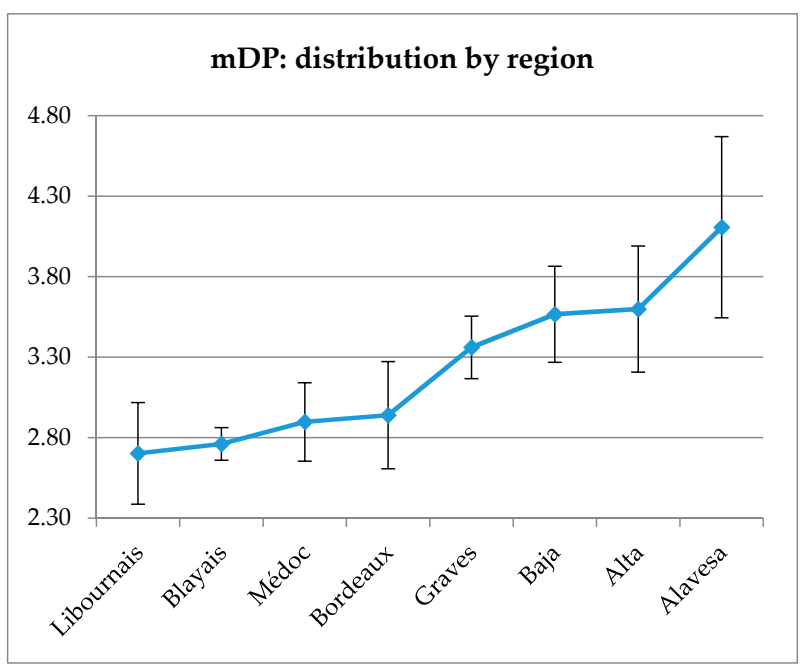

(a)

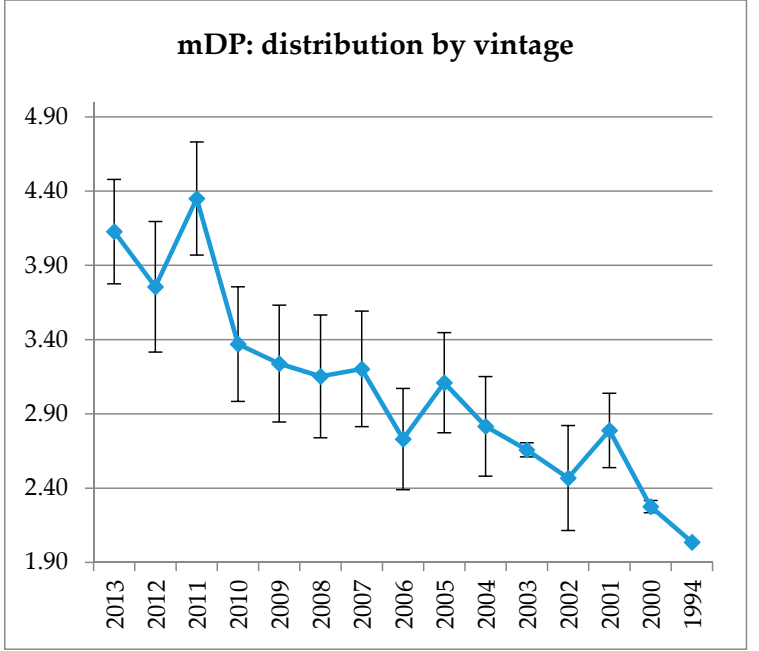

(b)

Figure A2. Mean degree of polymerization distributed by region (a) and vintage (b). Error bars are standard deviation of wine samples within each category.

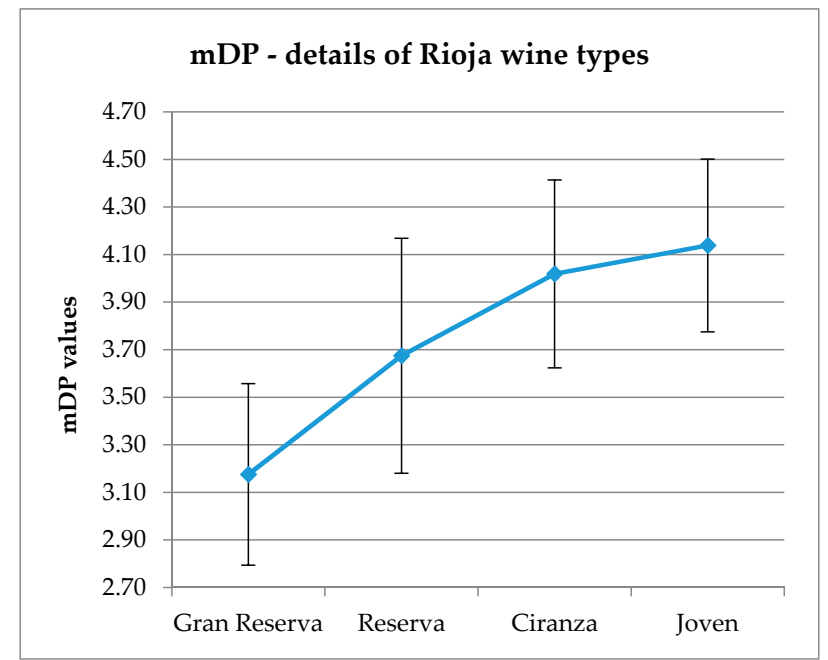

Figure A3. Mean degree of polymerization distributed by Rioja wine "types". Error bars are standard deviation of wine samples within each category. 


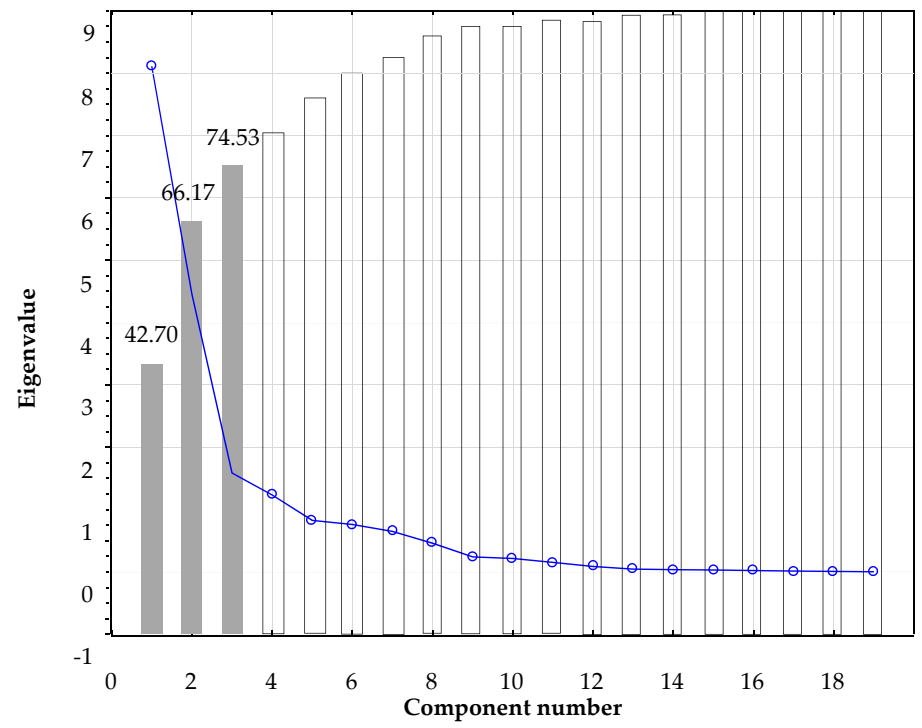

Figure A4. Principal components scree plot.

\section{References}

1. Mazza, G.; Francis, F.J. Anthocyanins in grapes and grape products. Crit. Rev. Food Sci. Nutr. 1995, 35, 341-371. [CrossRef] [PubMed]

2. Busse-Valverde, N.; Gómez-Plaza, E.; López-Roca, J.M.; Gil-Muñoz, R.; Bautista-Ortín, A.B. The extraction of anthocyanins and proanthocyanidins from grapes to wine during fermentative maceration is affected by the enological technique. J. Agric. Food Chem. 2011, 59, 5450-5455. [CrossRef] [PubMed]

3. Vidal, S.; Hayasaka, Y.; Meudec, E.; Cheynier, V.; Skouroumounis, G. Fractionation of grape anthocyanin classes using multilayer coil countercurrent chromatography with step gradient elution. J. Agric. Food Chem. 2004, 52, 713-719. [CrossRef] [PubMed]

4. Oliveira, J.; da Silva, M.A.; Jorge Parola, A.; Mateus, N.; Brás, N.F.; Ramos, M.J.; de Freitas, V. Structural characterization of a A-type linked trimeric anthocyanin derived pigment occurring in a young Port wine. Food Chem. 2013, 141, 1987-1996. [CrossRef] [PubMed]

5. Fulcrand, H.; Doco, T.; Es-Safi, N.-E.; Cheynier, V.; Moutounet, M. Study of the acetaldehyde induced polymerisation of flavan-3-ols by liquid chromatography-ion spray mass spectrometry. J. Chromatogr. A 1996, 752, 85-91. [CrossRef]

6. Bakker, J.; Bridle, P.; Honda, T.; Kuwano, H.; Saito, N.; Terahara, N.; Timberlake, C.F. Identification of an anthocyanin occurring in some red wines. Phytochemistry 1997, 44, 1375-1382. [CrossRef]

7. Rentzsch, M.; Schwarz, M.; Winterhalter, P.; Blanco-Vega, D.; Hermosín-Gutiérrez, I. Survey on the content of vitisin A and hydroxyphenyl-pyranoanthocyanins in Tempranillo wines. Food Chem. 2010, 119, 1426-1434. [CrossRef]

8. Marquez, A.; Dueñas, M.; Serratosa, M.P.; Merida, J. Formation of vitisins and anthocyanin-flavanol adducts during red grape drying. J. Agric. Food Chem. 2012, 60, 6866-6874. [CrossRef] [PubMed]

9. Benabdeljalil, C.; Cheynier, V.; Fulcrand, H.; Hafiki, A.; Mosaddak, M.; Moutounet, M. Mise en évidence de nouveaux pigments formés par réaction des anthocyanes avec des métabolites de levure. Sci. Aliments 2000, 20, 203-220. [CrossRef]

10. Arapitsas, P.; Perenzoni, D.; Nicolini, G.; Mattivi, F. Study of Sangiovese wines pigment profile by UHPLC-MS/MS. J. Agric. Food Chem. 2012, 60, 10461-10471. [CrossRef] [PubMed]

11. He, J.; Santos-Buelga, C.; Silva, A.M.S.; Mateus, N.; de Freitas, V. Isolation and structural characterization of new anthocyanin-derived yellow pigments in aged red wines. J. Agric. Food Chem. 2006, 54, 9598-9603. [CrossRef] [PubMed]

12. Blanco-Vega, D.; López-Bellido, F.J.; Alía-Robledo, J.M.; Hermosín-Gutiérrez, I. HPLC-DAD-ESI-MS/MS Characterization of pyranoanthocyanins pigments formed in model wine. J. Agric. Food Chem. 2011, 59, 9523-9531. [CrossRef] [PubMed] 
13. Cameira-dos-Santos, P.-J.; Brillouet, J.-M.; Cheynier, V.; Moutounet, M. Detection and partial characterisation of new anthocyanin-derived pigments in wine. J. Sci. Food Agric. 1996, 70, 204-208. [CrossRef]

14. Cruz, L.; Teixeira, N.; Silva, A.M.S.; Mateus, N.; Borges, J.; de Freitas, V. Role of vinylcatechin in the formation of pyranomalvidin-3-glucoside-(+)-catechin. J. Agric. Food Chem. 2008, 56, 10980-10987. [CrossRef] [PubMed]

15. Oliveira, J.; Azevedo, J.; Silva, A.M.S.; Teixeira, N.; Cruz, L.; Mateus, N.; de Freitas, V. Pyranoanthocyanin dimers: A new family of turquoise blue anthocyanin-derived pigments found in port wine. J. Agric. Food Chem. 2010, 58, 5154-5159. [CrossRef] [PubMed]

16. Fulcrand, H.; Cheynier, V.; Oszmianski, J.; Moutounet, M. An oxidized tartaric acid residue as a new bridge potentially competing with acetaldehyde in flavan-3-ol condensation. Phytochemistry 1997, 46, 223-227. [CrossRef]

17. Alcalde-Eon, C.; Escribano-Bailón, M.T.; Santos-Buelga, C.; Rivas-Gonzalo, J.C. Changes in the detailed pigment composition of red wine during maturity and ageing: A comprehensive study. Anal. Chim. Acta 2006, 563, 238-254. [CrossRef]

18. Robichaud, J.L.; Noble, A.C. Astringency and bitterness of selected phenolics in wine. J. Sci. Food Agric. 1990, 53, 343-353. [CrossRef]

19. Monagas, M.; Bartolomé, B.; Gómez-Cordovés, C. Updated knowledge about the presence of phenolic compounds in wine. Crit. Rev. Food Sci. Nutr. 2005, 45, 85-118. [CrossRef] [PubMed]

20. Vidal, S.; Aagaard, O. Oxygen management during vinification and storage of Shiraz wine. Aust. N. Z. Wine Ind. J. 2008, 23, 56-63.

21. Baranowski, J.D.; Nagel, C.W. Isolation and identification of the hydroxycinnamic acid derivatives in white Riesling wine. Am. J. Enol. Vitic. 1981, 32, 5-13.

22. Oszmianski, J.; Ramos, T.; Bourzeix, M. Fractionation of phenolic compounds in red wine. Am. J. Enol. Vitic. 1988, 39, 259-262.

23. Frankel, E.N.; Waterhouse, A.L.; Teissedre, P.L. Principal phenolic phytochemicals in selected California wines and their antioxidant activity in inhibiting oxidation of human low-density lipoproteins. J. Agric. Food Chem. 1995, 43, 890-894. [CrossRef]

24. Soleas, G.J.; Dam, J.; Carey, M.; Goldberg, D.M. Toward the fingerprinting of wines: Cultivar-Related patterns of polyphenolic constituents in Ontario wines. J. Agric. Food Chem. 1997, 45, 3871-3880. [CrossRef]

25. Fernández, K.; Kennedy, J.A.; Agosin, E. Characterization of Vitis vinifera L. Cv. Carménère grape and wine proanthocyanidins. J. Agric. Food Chem. 2007, 55, 3675-3680. [CrossRef] [PubMed]

26. Prieur, C.; Rigaud, J.; Cheynier, V.; Moutounet, M. Oligomeric and polymeric procyanidins from grape seeds. Phytochemistry 1994, 36, 781-784. [CrossRef]

27. Souquet, J.M.; Cheynier, V.; Brossaud, F.; Moutounet, M. Polymeric proanthocyanidins from grape skins. Phytochemistry 1996, 43, 509-512. [CrossRef]

28. Arozarena, I.; Ayestarn, B.; Cantalejo, M.; Navarro, M.; Vera, M.; Abril, I.; Casp, A. Anthocyanin composition of Tempranillo, Garnacha and Cabernet Sauvignon grapes from high- and low-quality vineyards over two years. Eur. Food. Res. Technol. 2002, 214, 303-309. [CrossRef]

29. Núñez, V.; Monagas, M.; Gomez-Cordovés, M.C.; Bartolomé, B. Vitis vinifera L. cv. Graciano grapes characterized by its anthocyanin profile. Postharvest Biol. Technol. 2004, 31, 69-79. [CrossRef]

30. González-SanJosé, M.L.; Diez, C. Caracterización varietal en función de la composición antociánica de la uva: análisis discriminante. Agrochimica 1993, 37, 86-92.

31. Lanaridis, P.; Bena Tzourou, I. Study of anthocyanins' variations during the ripening of 5 vine red varieties cultivated in Greece. J. Int. Sci. Vigne Vin 1997, 31, 205-212. [CrossRef]

32. Hebrero, E.; Santos-Buelga, C.; Rivas-Gonzalo, J.C. High performance liquid Chromatography diode array spectroscopy identification of anthocyanins of Vitis vinifera variety Tempranillo. Am. J. Enol. Vitic. 1988, 39, 227-233.

33. Wulf, L.; Nagel, C.W. High-Pressure liquid chromatographic separation of anthocyanins of Vitis vinifera. Am. J. Enol. Vitic. 1978, 29, 42-49.

34. Mateus, N.; de Freitas, V. Evolution and stability of anthocyanin-derived pigments during port wine ageing. J. Agric. Food Chem. 2001, 49, 5217-5222. [CrossRef] [PubMed]

35. Schwarz, M.; Quast, P.; von Baer, D.; Winterhalter, P. Vitisin A Content in Chilean wines from Vitis vinifera cv. Cabernet Sauvignon and contribution to the color of aged red wines. J. Agric. Food Chem. 2003, 51, 6261-6267. [CrossRef] [PubMed] 
36. Mateus, N.; Silva, A.M.S.; Vercauteren, J.; de Freitas, V. Occurrence of anthocyanin-derived pigments in red wines. J. Agric. Food. Chem. 2001, 49, 4836-4840. [CrossRef] [PubMed]

37. Sánchez Martínez, M.B. Pigmentos Derivados Antociánicos de los Vinos tintos de Rioja. Estudio Analítico, Influencia en el Color y Evolución Durante la Crianza. Ph.D. Thesis, Universidad del Pais Vasco/Euskal Herriko Unibertsitatea, Leoia, Spain, 2010.

38. Rasines-Perea, Z. Study of the Evolution of Anthocyanins, Tannins and Derivatives during Making and Ageing of red Wine from Rioja by FT-IR and HPLC-MS/MS. Ph.D. Thesis, Universidad del Pais Vasco/Euskal Herriko Unibertsitatea, Spain, Leoia, 2014.

39. Monagas, M.; Gómez-Cordovés, C.; Bartolomé, B.; Laureano, O.; Ricardo da Silva, J.M. Monomeric, oligomeric, and polymeric flavan-3-ol composition of wines and grapes from Vitis vinifera L. cv. Graciano, Tempranillo, and Cabernet Sauvignon. J. Agric. Food Chem. 2003, 51, 6475-6481. [CrossRef] [PubMed]

40. Chira, K.; Pacella, N.; Jourdes, M.; Teissedre, P.-L. Chemical and sensory evaluation of Bordeaux wines (Cabernet-Sauvignon and Merlot) and correlation with wine age. Food Chem. 2011, 126, 1971-1977. [CrossRef] [PubMed]

41. Freitas, V.A.P.D.; Glories, Y.; Monique, A. Developmental changes of procyanidins in grapes of red Vitis vinifera varieties and their composition in respective wines. Am. J. Enol. Vitic. 2000, 51, 397-403.

42. Jorge, M.; Ricardo-da-Silva, J.P.R. Dimer and trimer procyanidins in Carignan and Mourvedre grapes and wines. Vitis 1992, 31, 55-63.

43. González-Manzano, S.; Santos-Buelga, C.; Pérez-Alonso, J.J.; Rivas-Gonzalo, J.C.; Escribano-Bailón, M.T. Characterization of the mean degree of polymerization of proanthocyanidins in red wines using liquid chromatography-mass spectrometry (LC-MS). J. Agric. Food Chem. 2006, 54, 4326-4332. [CrossRef] [PubMed]

44. Li, Q.; Liu, Y.-X.; Pan, Q.-H.; Duan, C.-Q.; Shi, Y. Comparison of proanthocyanidins with different polymerisation degrees among berry skins of Shiraz, Cabernet Sauvignon, and Marselan. S. Afr. J. Enol. Vitic. 2014, 35, 51-58. [CrossRef]

45. Drinkine, J.; Lopes, P.; Kennedy, J.A.; Teissedre, P.-L.; Saucier, C. Analysis of ethylidene-bridged flavan-3-ols in wine. J. Agric. Food Chem. 2007, 55, 1109-1116. [CrossRef] [PubMed]

46. Chira, K.; Jourdes, M.; Teissedre, P.-L. Cabernet sauvignon red wine astringency quality control by tannin characterization and polymerization during storage. Eur. Food Res. Technol. 2011, 234, 253-261. [CrossRef]

47. Lorrain, B.; Chira, K.; Teissedre, P.-L. Phenolic composition of Merlot and Cabernet-Sauvignon grapes from Bordeaux vineyard for the 2009-vintage: Comparison to 2006, 2007 and 2008 vintages. Food Chem. 2011, 126, 1991-1999. [CrossRef] [PubMed]

48. Chira, K. Structures Moléculaires et Perception Tannique des Raisins et des vins (Cabernet-Sauvignon, Merlot) du Bordelais. Ph.D. Thesis, Université de Bordeaux Segalen (Bordeaux 2), Bordeaux France, 2009.

49. Ribéreau-Gayon, P.; Stonestreet, E. Determination of anthocyanins in red wine. Bull. Soc. Chim. Fr. 1965, 9 , 2649-2652. [PubMed]

50. Méthode OIV-MA-AS315-11,R.E. Détermination par CLHP de Neuf Anthocyanes Principales Dans le vin, 2007. International Organization of Vine and Wine. Available online: http:/ /www.oiv.int/public/medias/ 2389/oiv-ma-as315-11.pdf (accessed on 31 January 2012).

51. Sánchez-Ilarduya, M.B. Pigmentos Derivados Antociánicos de los Vinos Tintos de Rioja. Estudio Analítico, Influencia en el Color y Evolución Durante la Crianza. Ph.D. Thesis, Universidad del País Vasco, Leoia, Spain, 2010.

52. Ribéreau-Gayon, P.; Stonestreet, E. Dosage des tanins du vin rouge et détermination de leur structure. Chim. Anal. 1966, 48, 188.

53. Sánchez-Fernández, C. Búsqueda de Marcadores de Tipo Tanino en Vinos Tintos de Rioja: Estudio Cualitativo y Cuantitativo por HPLC-MS/MS. Ph.D. Thesis, Universidad del País Vasco, Leoia, Spain, 2012.

Sample Availability: Not available.

(C) 2017 by the authors; licensee MDPI, Basel, Switzerland. This article is an open access article distributed under the terms and conditions of the Creative Commons Attribution (CC BY) license (http:/ / creativecommons.org/licenses/by/4.0/). 